\title{
Online Collaborative Writing in Arabic as a Second Language Classroom: a Mixed-Method Study
}

\author{
Mohammed A. Alwaleedi \\ King Abdulaziz University, Jeddah, Saudi Arabia
}

DOI: http://doi.org/ 10.36892/ijlls.v2i4.459

\begin{tabular}{|c|c|}
\hline $\begin{array}{l}\operatorname{Rec} \\
30 / 0\end{array}$ & $\begin{array}{c}\text { Abstract } \\
\text { Thiction }\end{array}$ \\
\hline & $\begin{array}{l}\text { difference in their writing performance before and after the implementation of } \\
\text { OCW. This study employed a mixed-method approach, a qualitative case study } \\
\text { and a one-group experimental with pre-and post-test design, involving } 16\end{array}$ \\
\hline $\begin{array}{l}\text { Keywords: } \\
\text { Online collaborative } \\
\text { writing; Arabic as a } \\
\text { second language; } \\
\text { mixed-method } \\
\text { research; learners' } \\
\text { perception; } \\
\text { learners' interaction }\end{array}$ & $\begin{array}{l}\text { students who participated in the ASL writing class. The data included } \\
\text { observations, document analysis, in-depth interviews, questionnaires, and } \\
\text { tests. Pre- and post-test results were compared to analyze whether or not } \\
\text { there is a statistically significant difference in students' ASL writing skills } \\
\text { before and after the implementation of OCW. The findings showed variations } \\
\text { in interaction patterns during online collaborative writing activities. The } \\
\text { students had a positive perception of the implementation of OCW while the } \\
\text { results indicated a statistically significant difference in students' ASL writing } \\
\text { skills before and after the implementation of OCW. }\end{array}$ \\
\hline
\end{tabular}

\section{INTRODUCTION}

Over the last decades, collaborative writing $(\mathrm{CW})$ has been used in $\mathrm{L} 2$ classrooms as an essential teaching practice. In collaborative writing, the students interact, negotiate meaning, and take joint decisions during the writing cycle (Storch, 2013, 2019). CW provides students with valuable opportunities to co-construct knowledge and writing through scaffolded interactions (Swain, 1995; Swain \& Lapkin, 1998). Previous studies reported many benefits of CW, enhanced audience awareness, increased attention to language forms and discourse, and opportunities to apply newlylearned knowledge (DiCamilla \& Anton, 1997; Hirvela, 1999; Storch, 2013; Swain \& Lapkin, 1998). Along with the advancement of technology, the computer-mediated interactive literature has gained a growing interest in the second language and foreign-language learning contexts by introducing Web 2.0 platforms (e.g., google docs, Wikis), which provide for collaboration and communication distinctively. With some features such as interactivity writing, time/space composition, and independence, online collaborative writing (OCW) is a promising research field.

The rapid growth of online technologies and environments has created new possibilities to build knowledge during writing interactions. While online environments provide various possibilities for collaborative writing, they increase the difficulty of writing compared to collaborative writing in face-to-face learning (Lowry \& Nunamaker, 2003). Participants are not physically present in electronic scenarios which may create problems for integrating individuals' efforts. In a more complicated context, teamwork tasks and the different forms in which members collaborate in collective writing are essential to producing the mission's best possible outcome.

Conceptually, online learning manifests the learner-centered learning model since it "strongly encourages active learning, collaborative learning, mastery of learning resources, and studentcontrolled learning process" (Simonson et al., 2015). This has also improved the independence of learners as they not only engage individually in the learning process following guidance from the 
teacher but also control their own learning time and evaluate the learning materials according to their needs. Using a computer and internet-based technology, instructors can refine learners' learning process to achieve a positive learning experience. 'Online collaborative writing/OCW' here refers to the strategy of writing in which the students collaboratively write a text with their peers through online delivery (using media such as Google Docs, Wiki, and so forth).

Several studies focused on the implementation of OCW. Stoddart et al. (2013) carried out a diverse study of collaborative writing using wiki-based projects and extracted best practice principles from that body of work. Their study revealed that many variables affect the success of collaborative writing in wiki-based projects: for example, L2 skills, peer and instructor feedback, and peer contribution. Stoddart et al. (2013) further suggest that other researchers explore facilitation knowledge and practices in wiki-based collaborative writing of various academic domains and professional disciplines. Ardiasih et al. (2019) studied Wiki's usage in writing argumentative essays to improve learners' skills. The study focuses on applying the OCW by Wiki practices and the reliability of OCW to improve the students' argumentative essays. The findings indicate that the OCW, using Wiki embedded into Moodle, greatly affects the development of students' argumentative writing abilities. The results also show that the students participated in the OCW very enthusiastically. Guasch et al. (2013) investigated the type of feedback that best improves collaborative writing quality and its effect on students' learning in an online environment. The study revealed that epistemic and suggestive feedback best improve the quality of collaborative writing performance. Such (2019) investigated how English language learners work as groups within their language proficiency levels to complete online writing assignments using wikis. The study uncovered that linguistic and directional scaffolding promote interaction and collaboration among members to finish the writing tasks. Woodrich \& Fan (2017) explored forms of promoting the involvement of English language learners of diverse language backgrounds using Google Docs. The study explored how students' engagement in anonymous collaborative writing via Google documents will contribute to further achievement in a language class. This study suggests that the use of Google Docs is helpful for students' language skills improvement. The research shows varying rates of performance and satisfaction for students in three styles of writing assignments. From this elaboration, it is revealed that, to date, there has been a little study that investigated the implementation of OCW in ASL classrooms.

To fill the gaps from the previous studies, this study investigated the implementation of OCW in ASL classrooms, focusing mainly on the engagement of ASL learners during the implementation of $\mathrm{OCW}$, the perception of ASL learners about the implementation of OCW, and whether or not there is any significant improvement of students' ASL writing performance after implementing OCW. In this study, the implementation of OCW used the Google Docs embedded in Blackboard Collaborate $(\mathrm{Bb})$. Google Docs is a free web-based application where documents and spreadsheets can be created, edited, stored and retrieved, online.

The objectives of this study were: (1) describing how ASL learners interact during the OCW tasks, (2) revealing ASL learners' perception on the implementation of OCW, and (3) examining whether or not there is a difference of students' ASL writing performance before and after the implementation of OCW.

The study asked the following research questions:

(1) How do ASL learners interact during OCW tasks? (2) How do ASL learners perceive the implementation of OCW? and (3) Is there any difference in students' ASL writing performance before and after the implementation of OCW?

\section{LITERATURE REVIEW}

Several studies have focused on investigating Online Collaborative Writing (OCW). Four major trends or patterns emerged from the studies, i.e., the integration of specific online platform/method/technique in OCW, the feasibility of specific platform to support OCW, students' perception on the use of the specific platform in OCW, and the coordination methods of students during OCW.

The first trend is the integration of specific online platform/method/technique in OCW (Ardiasih et al., 2019; Cho \& Lim, 2017; Katz \& Thoren, 2014; Such, 2019). Those studies showed a positive effect of integrating a specific online platform/method/technique in OCW. Cho \& Lim (2017) 
studied the impact of regulation activities on collaborative writing on wikis. The results indicated that the interventions significantly improved undergraduates' confidence in the use of writing techniques and significantly reduced the anxiety regarding teaching. When the log files were evaluated on wikis, several students engaged strongly in their wikis' collaborative writing. L. Wang (2019) examined how a regulatory activity influences peer interaction in OCW. The findings show that interaction patterns were calculated with regards to 'fair' and 'mutuality.' As these learners moved between roles, various interaction patterns emerged. An expanded model of behavior clarified the complexities of peer relationships. This research reinforced the evaluation of how the policy affected peer behaviors through social and cultural influences. This will offer perspectives into how regulatory practices for web-based collaborative writing tasks in L2 classes can be built and improved. Ardiasih et al. (2019) investigated the effectiveness of using wikis as a tool in the Online Collaborative Writing Technique (OCWT) to improve students' essay writing. Evidence from statistic assessments and examination of students' experiences has a major impact on developing students' argumentative writing abilities. Consequently, this methodology is highly suitable to refine learners' independence in studying.

The second trend is the feasibility of specific platforms to support OCW (Rahayu, 2016; Y. C. Wang, 2015; Woodrich \& Fan, 2017). Here two online platforms are commonly used in OCW: Wikis and Google Docs. Woodrich \& Fan (2017) explored how to utilize an online word processing platform to promote engagement among students of diverse backgrounds, including English Language Learners. The study explored, in particular, how participating students in anonymous collective writing through Google Docs will contribute to improve results in the English Language Arts classroom. The results showed that students with different language fluencies engaged more consistently staying anonymous while face-to-face correspondence showed best average ratings with students collaborating on Google Docs. Rahayu (2016) explored Google Docs' feasibility as the learning tool for non-English department students in OCW. The study showed that Google Docs is an appropriate learning resource for OCW, especially in English lessons. Online Collaborative Writing, by using Google Docs in a non-English language department, provides various emotional benefits, such as increasing student commitment to learning writing.

The third trend is the students' perception of specific platforms in OCW (An et al., 2008; Chao \& Lo, 2011; Farrah, 2015). The studies on these topics reveal students' positive perceptions of the implementation of OCW by using specific online platforms. Chao \& Lo (2011) conducted an investigation on English as a Foreign Language (EFL) students' perceptions of OCW by using Wiki. The findings showed a substantial percentage of students' satisfaction with the Wiki-based collaborative writing framework. The instructional nature of a 5-stage collaborative writing project on Wiki allowed EFL students complete a collaborative online writing assignment with fewer time constraints. Farrah (2015) investigated students' perceptions and attitudes of an English writing class towards OCW. The results indicated that online collaborative writing is a critical factor in improving learning motivation and learners' performance. The shared experience of online learning showed that the enthusiasm levels of the students increased. The participants positively took this experience by contributing to their communication skills, sharing thoughts within the party, receiving and offering valuable inputs, enhancing productivity by writing better essays, and inspiring them to think critically. All these help to make OCW a pleasant and enjoyable experience.

The fourth trend is students' coordination methods during OCW (Alghasab, 2015; Lowry \& Nunamaker, 2003; Nykopp et al., 2019). Nykopp et al. (2019) explored how students organized their online communication during the implementation of $\mathrm{OCW}$ and forms of coordinating profiles that exist between students. The findings showed that students coordinated their collaborative writing primarily through text-based activities, task-related activities, and social activities. The results also indicated that students have organized the collaborative writing process in various ways. Alghasab (2015) investigated the collaboration between students and students in Wiki mediated collaborative writing. The study revealed that developing a shared wiki culture, strengthening a sense of wiki community, asking students to participate with each other, becoming co-learners, and modeling editing behaviors all seem to promote collaboration. On the inverse, direct instructor edits, immediate responses, use a firm tone, and requests for inactive students promote involvement, but not necessarily collaboration. The interview data also indicated the impediment of socio-cultural problems such as teachers' dominance, dubious peer reviews, and individual text ownership. 


\section{METHOD}

\section{Research Design}

To achieve the objectives of the study, a mixed-method design was employed. The term 'mixed-methods' refers to an emerging approach to research which promotes the systematic integration, or "mix" of quantitative and qualitative data within a single study or a sustainable research program (Wisdom \& Creswell, 2013). The design's basis was that a single data set was not enough to deal with various research questions (Creswell \& Clark, 2011). Consequently, to accomplish the goals of this study well, an embedded one-group experimental with pre- and post-test research design was used (involving quantitative and qualitative data collection and analysis).

\section{Research Participants and Context}

The population of this study was 64 male adult ASL students distributed in 10 classes. They were enrolled in Arabic language preparation programs in the Arabic Language Institute. The students came from a wide range of first language backgrounds, such as French, German, Bahasa Indonesia, Malay, Urdu, Hindi, Bengali, Pashto, Dhivehi, Spanish, and Portuguese. These groups had similar features: The students' entry exam scores were considered to have a high-intermediate level of Arabic ability; They are aged 20-23 years old. Since they did not share a common language, Arabic was the only language in classroom instruction. This study was conducted in one class consisted of 16 students who were voluntarily becoming the participants. Then, the chosen class was treated using OCW for 12 weeks. Besides, the researcher also used a purposive sampling technique for conducting an in-depth interview. The participants' willingness to be interviewed and their availability influenced the sampling process.

This study was conducted in the Arabic Language Institute, Umm AlQura University, situated in Makkah, Saudi Arabia. The institute has three departments: Language and Culture, Teacher Training, and Teacher Preparation. The Language and Culture Department develops and administers a program for Arabic as a Second Language (ASL) teaching prepared for non-native speakers worldwide. During the enrollment process, the institute administers an ASL learner placement test to classify them into appropriate program levels as they have different levels of Arabic skills. This twoyear study consists of four semesters with 20 contact hours each week. The program's primary objective is to develop ASL learners' language skills and prepare them to continue in Saudi universities.

\section{Data Collection Methods and Instruments}

Data were collected through observation, document analysis, questionnaires, in-depth interviews, and tests (pre- and post-test) to achieve the study's goals. The detailed use of each method is presented in the following table:

Table 1 Research Objectives and their Methods of Data Collection

\begin{tabular}{cll}
\hline No. & \multicolumn{1}{c}{ Research Objectives/Goals } & \multicolumn{1}{c}{ Methods } \\
\hline 1 & Describing how ASL learners interact during the OCW tasks & $\begin{array}{l}\text { Observation, documents analysis, \& } \\
\text { in-depth interview } \\
\text { Questionnaires \& in-depth interview }\end{array}$ \\
3 & $\begin{array}{l}\text { Revealing ASL learners' perception of the implementation of } \\
\text { OCW } \\
\text { Examining whether or not there is a difference in students' ASL } \\
\text { writing performance before and after the implementation of OCW }\end{array}$ & Pre-test and post-test \\
\end{tabular}

The first method of data collection was observation field notes. During the class intervention with OCW, the researcher conducted an observation focusing on how the ASL students interact during OCW tasks. All information related to this was noted and written in the observation field notes.

The second method of data collection was document analysis. The 'documents' refer to Google Docs files that contained the results of students' essay writing. The Google Docs files can be traced to how the students coordinated with their peers and who worked actively and passively to achieve the tasks. 
The third method of data collection was in-depth interviews. The instrument used was the interview protocol. This in-depth interview was conducted by focusing on revealing how the ASL students interact with each other during OCW tasks and how the ASL learners perceived their experience in the implementation of OCW. This interview was done through the Zoom Meeting application and conducted after the 12-week implementation of OCW. Data from the interviews were recorded, collected, and transcribed for analysis.

The fourth method of data collection was questionnaire distribution. The questionnaire consisted of 22 statements with a 5-point Likert scale (strongly agree, agree, neutral, disagree, and strongly disagree) was developed. The questionnaire was adapted from Farrah (2015). The questionnaire was in the form of an online Google Form and distributed after the 12-week implementation of OCW. The questionnaire's reliability was also tested. The result shows that the questionnaire's overall Cronbach Alpha Coefficient is $(\mathrm{r}=0.89)$, which indicates that it has a very high degree of internal consistency. Therefore, the questionnaire is reliable. This questionnaire distribution was a source triangulation technique employed in this study to guarantee data validity (qualitative data).

The fifth method of data collection was the test (pre- and post-test) which was an essay writing test. The pre-test was administered at the beginning of the research prior to any treatment and the post-test at the end of the research after the OCW was implemented (after a 12-week intervention). During the 12-week intervention, the participants were given three types of writing tasks: descriptive, narrative, and argumentative texts. Each task (500-word text) was completed in three weeks (i.e., 50 minutes per meeting each week). During the classroom observation, the researcher observed how learners participated in co-constructing the writing tasks. This process included brainstorming, planning, drafting, and revising. Once OCW treatment had been completed, they have received a postwriting test to write 500-word descriptive texts. The test was performed individually, similar to the pre-test at the start of the activity.

\section{The technique of Data Analysis}

The study used two kinds of data: qualitative data, yielded from observation, document analysis, and in-depth interviews and qualitative data that focused on describing how ASL learners interact during the OCW tasks and reveal ASL learners' perceptions of the implementation of OCW. The qualitative data were analyzed by following Creswell's (2012) principles. The researchers first collect data and then prepare it for data analysis. This analysis initially consists of developing a general sense of the data, and then coding description and themes about the central phenomenon. In this study, coding schemes were used to gain a more detailed perspective about what was occurring based on the purpose of the study. These coding schemes helped to analyze the transcripts of the participants.

Besides qualitative data, there were also quantitative data yielded from questionnaires and tests. The quantitative data yielded from the questionnaire were analyzed using descriptive statistics. Meanwhile, the quantitative data yielded from the pre- and post-test. The pre- and post-tests were conducted to evaluate students' performance in ASL writing. Two scorers evaluated the students' works. This technique is known as inter-rater scoring (inter-rater reliability), in which the objective is to avoid the subjectivity of the scorer(s). Thus, the data were guaranteed to be valid. Then, these quantitative data were analyzed by using inferential statistics, in this case, using a paired sample t-test. Prior to the paired sample t-test, the prerequisite tests were also employed, i.e., normality and homogeneity test. All of these tests were done using the SPSS 22.0 program.

\section{RESULTS}

\section{ASL Learners' Interaction during the OCW Tasks}

The first objective of this study was to describe how ASL learners interact during OCW tasks. Observation during the implementation of OCW, document analysis, and in-depth interview at the end of the intervention time were conducted to achieve this objective. During the 12-week intervention, the participating class received three types of writing tasks, descriptive, narrative, and argumentative 
texts. Each task (500-word text) was completed in three weeks (i.e., 50 minutes each week). The researcher investigated how learners engaged in co-constructing writing tasks during an online classroom observation. It included brainstorming, planning, drafting, and revising.

From the observation, it was revealed that the instructor described how OCW worked for the students. The instructor emphasized the significance of mutual accountability in carrying out written assignments. The instructor acted to be an advisor. The instructor confirmed that the students understood the point of OCW at the start of the OCW task. The groups worked collaboratively at all stages of the writing tasks. They also had equal contributions and a high degree of commitment to each other's contributions.

In particular, the instructor emphasized the importance of shared responsibility to the group during the first OCW task to foster interdependence among group members when completing the writing tasks. For example, the instructor provided them with options on topic choices for writing tasks to start the activities, that is, students may develop the topics provided by the teacher or those agreed in their groups. Most participants decided to create their subjects during pre-writing activities. They chose a specific subject which is familiar to every group member.

Observation also revealed students' pattern of interaction. Some students have a pattern of (1) expert/novice interaction, where one- or two-party leaders served as experts while the others became novices. Here, the 'expert' members encouraged the 'novice' to participate actively in group work. Sometimes, when the task was difficult, they guided and supported the novice. Some students also have (2) dominant/passive interaction. In this case, the dominant students took more chances to achieve OCW tasks. The other groups have (3) dominant/dominant and (4) collaborative patterns interactions.

Document analysis, which was in the form of students' Google Docs files and was traced through the students' shared links. It revealed how the students divided the tasks and communicated among group members to achieve OCW tasks. It revealed how each group divided the tasks among group members based on the paragraph. Each group member got one paragraph to complete for each essay, i.e., introductory paragraph, body paragraph 1 , body paragraph 2 , body paragraph 3 . Meanwhile, for the concluding paragraph, they worked together to complete it. This task division worked for all writing stages, i.e., brainstorming, planning, drafting, and revising. However, each student had an equal chance to give comments, suggestions, and corrections to their peer's works.

The document analysis also revealed that through group members' interaction (in the forms of comments found in the Google Docs files), they proposed ideas and put them together to achieve OCW tasks. Engagement of the learners brought out each member of the group's skills and competencies to create complementary contributions to the jointly produced texts. Negotiation traits such as clarification queries and comprehension checks were also found in the documents.

The results yielded from observation and document analysis were triangulated by using an indepth interview with students which confirmed that prior to OCW tasks, the instructor explained what OCW is and how it works as well as explained the importance of collaborative work even though in an online environment, building positive interdependence among group members, and so on.

The following is the interview excerpt:

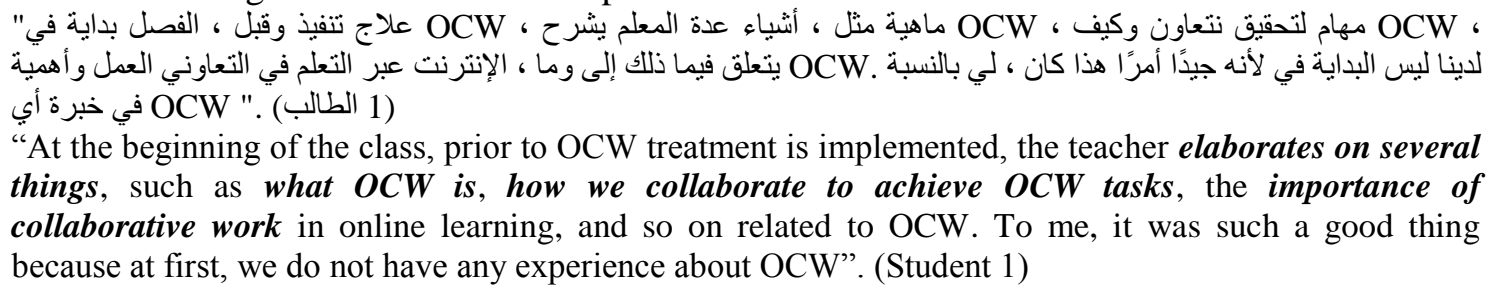

It was also confirmed that the students divided the given tasks about essay writing to each group member based on each paragraph. Each group member had to finish a paragraph for each essay, i.e., introduction paragraph, body paragraph 1 , body paragraph 2 , and body paragraph 3 . In the meantime, they were working together to finalize the conclusion paragraph. The task division works for all writing phases, i.e., brainstorming, planning, drafting, and revising.

The following is the interview excerpt: 


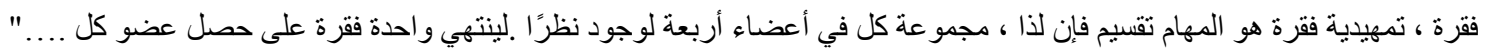

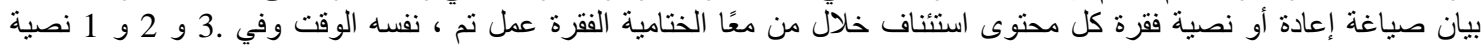

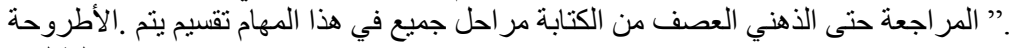

(3)

“.... Each member got one paragraph to finish. Since there were four members in each group, the task divisions were introductory paragraphs, body paragraphs 1, 2, and 3. Meanwhile, the concluding paragraph was done together by resuming each body paragraph's content or restating the thesis statement. This task division is done in all writing stages from brainstorming until revising". (Student 3)

Finally, the in-depth interview also confirmed that during the interaction through Google Docs, the major themes that each group discussed were proposing ideas, clarifying queries, and checking for understanding. The following is the interview excerpt:

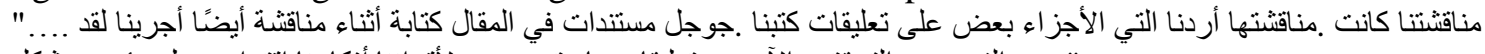

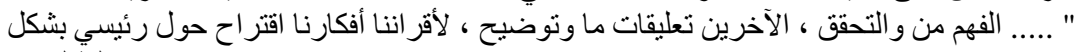

(4) (الطُالب)

".... We also conducted a discussion while writing the essay in Google Docs. We wrote comments on some parts that we wanted to discuss. Our discussion was mainly about proposing our ideas to our peers, doing clarification of what others' comments, and checking for understanding .....". (Student 4)

To sum up, the results of this study dealing with the first objective is presented in the following table:

Table 2: The Summary of ASL Learners Interaction during OCW Tasks

\begin{tabular}{|c|c|c|}
\hline Cases & Students' Interaction & Teacher's Intervention \\
\hline Group 1 & $\begin{array}{l}\text { - } \quad \text { expert/novice pattern } \\
\text { dividing task based on the paragraph of an } \\
\text { essay (each member got } 1 \text { paragraph to } \\
\text { finish), except the concluding paragraph } \\
\text { online discussion through Google Docs } \\
\text { about ideas, negotiation (doing } \\
\text { clarification and checking for }\end{array}$ & $\begin{array}{ll}- & \text { Prior to any treatment: } \\
- & \text { explaining what OCW is } \\
\text { - } & \text { explaining how OCW works } \\
- & \text { explaining the importance of collaborative } \\
& \text { works } \\
\text { - } & \text { explaining how to build positive } \\
& \text { interdependence among group members }\end{array}$ \\
\hline
\end{tabular}

\begin{tabular}{|c|c|}
\hline Group 2 & 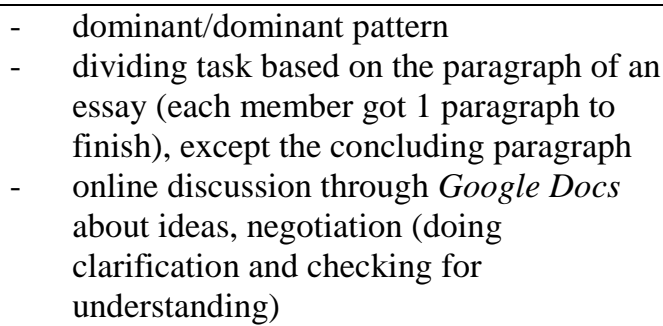 \\
\hline Group 3 & $\begin{array}{ll}\text { - } & \text { dominant/passive pattern } \\
\text { - } & \text { dividing task based on the paragraph of an } \\
\text { essay (each member got } 1 \text { paragraph to } \\
\text { finish), except the concluding paragraph } \\
\text { - } \\
\text { online discussion through Google Docs } \\
\text { about ideas, negotiation (doing } \\
\text { clarification and checking for } \\
\text { understanding) }\end{array}$ \\
\hline Group 4 & $\begin{array}{l}\text { - } \quad \text { collaborative pattern } \\
\text { dividing task based on the paragraph of an } \\
\text { essay (each member got } 1 \text { paragraph to } \\
\text { finish), except the concluding paragraph } \\
\text { - } \text { online discussion through Google Docs } \\
\text { about ideas, negotiation (doing } \\
\text { clarification and checking for } \\
\text { understanding) }\end{array}$ \\
\hline
\end{tabular}




\section{ASL Learners' Perception on the Implementation of OCW}

The second objective of this study was to reveal ASL learners' perceptions of the implementation of OCW. To achieve this objective, a questionnaire and an in-depth interview were conducted. The results of questionnaire distribution are presented in the following table:

Table 3: Mean and Standard Deviation for all Items in the Questionnaire

\begin{tabular}{|c|c|c|c|c|}
\hline No. & Statements & $\mathbf{N}$ & Mean & $\begin{array}{c}\text { Std. } \\
\text { Deviation }\end{array}$ \\
\hline 12 & $\begin{array}{l}\text { OCW activities with Google Docs enable me to learn new ways to } \\
\text { plan \& edit my essays }\end{array}$ & 16 & 4.88 & 0.34 \\
\hline 17 & $\begin{array}{l}\text { Overall, the OCW activities with Google Docs are a worthwhile } \\
\text { experience }\end{array}$ & 16 & 4.81 & 0.40 \\
\hline 10 & OCW activities with Google Docs should be encouraged & 16 & 4.69 & 0.48 \\
\hline 16 & $\begin{array}{l}\text { Through the OCW activities with Google Docs, we write better } \\
\text { essays }\end{array}$ & 16 & 4.63 & 0.50 \\
\hline 5 & $\begin{array}{l}\text { OCW activities with Google Docs help me to have a greater } \\
\text { responsibility for myself \& my group }\end{array}$ & 16 & 4.56 & 0.51 \\
\hline 9 & OCW activities with Google Docs improve my performance & 16 & 4.56 & 0.51 \\
\hline 18 & $\begin{array}{l}\text { OCW activities with Google Docs help me acquire relevant } \\
\text { computer knowledge and skills }\end{array}$ & 16 & 4.50 & 0.52 \\
\hline 21 & $\begin{array}{l}\text { OCW activities with Google Docs motivate me to interact with my } \\
\text { group members outside of class }\end{array}$ & 16 & 4.50 & 0.52 \\
\hline 4 & $\begin{array}{l}\text { OCW activities with Google Docs help me to receive useful } \\
\text { feedback }\end{array}$ & 16 & 4.44 & 0.51 \\
\hline 20 & $\begin{array}{l}\text { OCW activities with Google Docs motivate me to complete tasks } \\
\text { assigned by my instructor }\end{array}$ & 16 & 4.44 & 0.51 \\
\hline 15 & I get more work done when I work with others & 16 & 4.25 & 0.68 \\
\hline 14 & $\begin{array}{l}\text { I enjoy writing more than I did before due to OCW activities with } \\
\text { Google Docs }\end{array}$ & 16 & 4.19 & 0.66 \\
\hline 22 & $\begin{array}{l}\text { I feel less stressed when I do OCW activities with Google Docs to } \\
\text { complete the essay project }\end{array}$ & 16 & 4.19 & 0.75 \\
\hline 11 & $\begin{array}{l}\text { OCW activities with Google Docs enable me to have more } \\
\text { confidence in working with other students }\end{array}$ & 16 & 4.06 & 0.77 \\
\hline 13 & $\begin{array}{l}\text { OCW activities with Google Docs give me the chance to express } \\
\text { my ideas in the group }\end{array}$ & 16 & 4.00 & 0.52 \\
\hline 19 & $\begin{array}{l}\text { OCW activities with Google Docs make me a better user of } \\
\text { computer and technology }\end{array}$ & 16 & 4.00 & 0.63 \\
\hline 6 & $\begin{array}{l}\text { OCW activities with Google Docs enhance my communication } \\
\text { skills }\end{array}$ & 16 & 3.56 & 0.51 \\
\hline 1 & $\begin{array}{l}\text { OCW activities with Google Docs foster the exchange of } \\
\text { knowledge, information, \& experience }\end{array}$ & 16 & 3.50 & 0.52 \\
\hline 3 & $\begin{array}{l}\text { OCW activities with Google Docs stimulate my creative thinking } \\
\text { skills }\end{array}$ & 16 & 3.50 & 0.52 \\
\hline 8 & OCW activities with Google Docs enhance my Interpersonal skills & 16 & 3.38 & 0.50 \\
\hline 7 & OCW activities with Google Docs enhance my negotiation skills & 16 & 3.00 & 0.73 \\
\hline 2 & OCW activities with Google Docs make problem-solving easier & 16 & 2.94 & 0.68 \\
\hline
\end{tabular}

The table above indicates that students are very optimistic about the OCW experience. Most students saw the experience as a satisfying opportunity and a worthwhile experience, as seen in item 17. Moreover, because of this rewarding experience, they support item 12, in which the OCW experience enables them to learn new ways to plan and edit essays. Therefore, they perceive that OCW activities with Google Docs should be encouraged (item 10).

The rating of items 17 and 10 is very high $(M=4.81$ and 4.69). The students promoted this type of experience because OCW activities with Google Docs helped them write a better essay, as set out in item $16(\mathrm{M}=4.63)$, and to have a high responsibility to themselves and their group (item 5, $\mathrm{M}=4.56$ ). They favored this way of learning because it improves their writing performance, helps them gain computer expertise, motivates them to interact with their peers outside the class, helps them 
have feedback exchange with their peers, and motivates them to complete their essays, as set out in points $9,18,21,4$, and 20 , with very high ratings.

Table 3 also shows that OCW activities with Google Docs have the following advantages, which make the experience worthwhile as set out in item 17:

- Learners could do more work when they work with others/in a group

- Learners feel more enjoyable and less stressed to do OCW task

- Learners have more confidence to work with others

- Learners have more opportunities to express their ideas and opinions to others

- Learners can improve their communication skills

- Learners become better users of computer and technology

- Learners gain relevant information and can promote an exchange of knowledge

- Learners can stimulate their creative thinking skills

Students, however, gave lower ratings on items numbers 8, 7, and 2. The students had neutral opinions when asked whether or not the OCW activities with Google Docs can stimulate interpersonal skills, negotiation skills, and problem-solving skills. Those items have a relatively low rating, as the table shows. However, given the tremendous benefits that can be learned from this activity, we can accept these slight disadvantages. For all, the benefits outweigh the drawbacks.

The results of the in-depth interview also confirm the students' perception of the implementation of OCW. The students stated that OCW activities are valuable since it gives them many benefits, as mentioned in the previous paragraphs.

The followings are the interview excerpts:

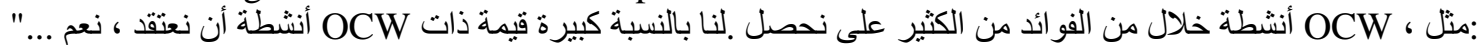
، فردًا وليس ، جماعية مهمة هذه أن نعتقد لأننا ربما .أقل بتوتر ونشعر متعة أكثر ويجعلنا تعاوني بشكل بالمهام القيام يمكنتا

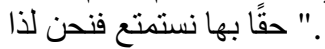

(5) ( 2 الطالب)

“... Yes, we think that OCW activities are precious for us. We get many benefits through OCW activities, such as we can do the tasks collaboratively, and it makes us more enjoy and feel less stressed. It is probably because we think that this is a group task, not an individual, so we enjoy it". (Student 5)

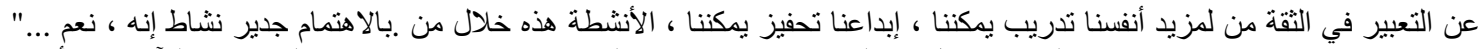
" التعاون خلال من الكتابة تحسين يمكننا وبالطبع ، جديدة تقنية مهار ات تعلم يمكننا ، للآخرين الأفكار

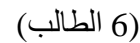

“... Yeah, it is a worthwhile activity. By those activities, we can stimulate our creativity, we can train ourselves to have more confidence in expressing ideas to others, we can learn new technology skills, and of course, we can improve our writing through collaboration". (Student 6)

\section{ASL Learners' Writing Performance before and after the Implementation of OCW}

The pre- and post-test results of the group are the variables analyzed in this part. The pre- and post-tests were conducted to evaluate students' performance in ASL writing. Two scorers evaluated the students' works. This technique is known as inter-rater scoring (inter-rater reliability), in which the objective is to avoid the subjectivity of the scorer(s). So, the data were guaranteed its validity. The paired sample t-test was carried out to determine whether or not there was a significant difference in ASL learners' writing skills before and after the implementation of OCW. Before the paired sample ttest was carried out, two prerequisite tests, i.e., normality and homogeneity tests, were also conducted to the pre-and-post test scores.

After the data were tested for their normality and homogeneity, the last step was the paired sample t-test. It was done whether there is a significant difference between the mean of pre-test scores and post-test scores.

Table 4: Paired Samples T-Test Paired Differences

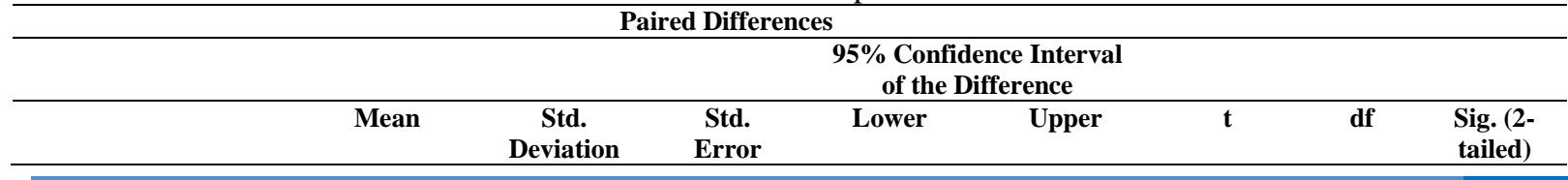




\begin{tabular}{|c|c|c|c|c|c|c|c|c|c|}
\hline & & & & Mean & & & & & \\
\hline Pair 1 & $\begin{array}{l}\text { Pretest } \\
\text { score - } \\
\text { Posttest } \\
\text { score }\end{array}$ & -19.25000 & 3.46410 & .86603 & -21.09589 & -17.40411 & -22.228 & 15 & .000 \\
\hline
\end{tabular}

Table 8 shows the result of the paired sample test. It reveals that the Sig. (2-tailed) ( $p=.000$, $p<.05)$, which means that there is a statistically significant difference in students' ASL writing performance before and after the intervention (OCW).

\section{DISCUSSION}

\section{RQ 1: How do ASL learners interact during OCW tasks?}

Dealing with this research question, this study's findings reveal four patterns of interaction applied by ASL learners during OCW tasks. Those four interaction patterns are expert/novice, dominant/passive, dominant/dominant, and collaborative. These findings are in line with the theory of Storch (2002). Storch (2002) states that the primary patterns for interaction between group members during collaborative writing tasks are (1) collaborative (i.e., when group members worked together, mediated, participated in all the tasks), (2) dominant/passive (i.e., one or two group members dominated the group work while the others took an increasingly passive position), (3) cooperative (i.e., since there was no long monolog when the group members were negotiating the written tasks, the label 'cooperative' was used instead of 'dominant/dominant'), and (4) expert/novice (i.e., when one or two group members were acting as a 'expert' inviting other members to participate and to assist them during the tasks.

The study's findings also revealed that students had the potential to suggest ideas and bring them together to execute OCW tasks through the interaction between the participants of the group (in the forms of comment contained in the Google doc files). The students' contribution drew each member of the group's skills and abilities to provide complementary contributions to the texts produced jointly. The documents also found negotiating characteristics such as clarification inquiries and comprehension checks. Storch (2005) asserts that interaction in collaborative writing enables students to communicate on different written work aspects. It encouraged students, in particular, to collaborate in generating ideas. Further, it also provides students the ability to give and receive direct inputs about language, which is overlooked when individual students write.

\section{RQ 2: How do ASL learners perceive the implementation of OCW?}

The study's findings show that the students have a positive perception of OCW activities with Google Docs. They perceived that OCW with Google Docs are worthwhile activities. The findings presented in Table 3 above are consistent with several studies which demonstrate learners' positive attitudes towards online collaborative writing since it can improve learners' achievement, allow learners promote collaborative responsibility, enable students work with their essay writing creatively, stimulate learners to learn new computer skills, raise learners' motivation and self-confidence, allow learners share their ideas, and stimulate learners' creative thinking skills (Aydin \& Yildiz, 2014; Brodahl \& Hansen, 2014; Chou \& Chen, 2008; Farrah, 2015; Suwantarathip \& Wichadee, 2014; Zhou et al., 2012). In addition, other studies also claim that innovation and critical thinking are also encouraged in online collaborative environments (Gokhale, 1995; Grami, 2012). Chou \& Chen (2008) assert that online collaborative writing motivates students to engage in collaborative learning and facilitate learning outcomes. Moreover, Ciftci \& Kocoglu (2012) confirm that, in their revised texts, the students had better quality after work in online collaborative writing.

\section{RQ 3: Is there any difference in students' ASL writing performance before and after the implementation of $\mathrm{OCW}$ ? \\ The result of the paired sample t-test reveals that the Sig. (2-tailed) $(p=.000, p<.05)$, which means that there is a statistically significant difference in students' ASL writing performance before and after the implementation of OCW. OCW activities may have contributed to the better performance of students in the post-test writing. They shared and expressed their best ideas in writing and learned from each other. Therefore, they could develop their skills in writing. These findings}


support earlier studies (Sajedi, 2014; Shehadeh, 2011) that collaborative writing has a major influence on the increase of students' writing performance at L2, especially in material, organization and vocabulary, but not in grammar and mechanicals. One potential reason for the lack of relevance is that students have minimal knowledge and understanding of the given subjects. However, they also found it challenging to select appropriate vocabulary to write when they complete their tasks. All these variables may have caused OCW to have unpredictable effects on some areas of writing. In general, the most critical effect of OCW is the significant progress in writing by the students in terms of organization, sentences, and mechanics.

\section{CONCLUSION}

This study aimed at (1) describing how ASL learners interact during the OCW tasks, (2) revealing ASL learners' perception on the implementation of OCW, and (3) examining whether or not there is a difference in students' ASL writing performance before and after the implementation of OCW. From the observation, document analysis, and in-depth interview, it was found that the ASL learners did $\mathrm{OCW}$ interaction by using four patterns, i.e., expert/novice, dominant/passive, dominant/dominant (cooperative), and collaborative. OCW activities improve their ability to interact meaningfully. Therefore, they were able to produce ideas and pool them to complete OCW tasks.

The data yielded from the questionnaire and in-depth interviews reveal that students have a positive perception of the implementation of OCW activities. They perceived OCW to be a worthwhile activity due to its positive effects on students' writing performance. The statistical analysis results support students' perceptions by using a paired sample t-test, which compares the students' ASL writing performance before and after the treatment by OCW. The result shows the significant improvement of students' ASL writing performance after being treated using OCW tasks.

The findings of this study, however, require cautious interpretations. There are some uncontrollable variables during pedagogical experiments. Besides, this study had sample size limitations and short timeframes. Although, in this context, the researcher can demonstrate the effectiveness of OCW, however, it is not suggested to generalize these findings. Consequently, for further research, it is suggested to examine how OCW contributes to L2 learning in writing in a broader context, larger sample size, and more extended timeframe.

\section{REFERENCES}

Alghasab, M. (2015). Student-student collaboration in wiki mediated collaborative writing activities: Exploring EFL teachers' roles in the collaborative process. PhD Thesis. University of York, Education.

An, H., Kim, S., \& Kim, B. (2008). Teacher perspectives on online collaborative learning: Factors perceived as facilitating and impeding successful online group work. Contemporary Issues in Technology and Teacher Education, 8(1), 65-83.

Ardiasih, L. S., Emzir, \& Rasyid, Y. (2019). Online collaborative writing technique using wiki: How effective is it to enhance learners' essay writing? Journal of Asia TEFL, 16(2), 531-546. https://doi.org/10.18823/asiatefl.2019.16.2.6.531

Aydin, Z., \& Yildiz, S. (2014). Using wikis to promote collaborative EFL writing. Language Learning and Technology, 18(1), 160-180.

Brodahl, C., \& Hansen, N. K. (2014). Education students' use of collaborative writing tools in collectively reflective essay papers. Journal of Information Technology Education:Research, 13(1), 91-120. https://doi.org/10.28945/1960

Chao, Y. C. J., \& Lo, H. C. (2011). Students' perceptions of Wiki-based collaborative writing for learners of English as a foreign language. Interactive Learning Environments, 19(4), 395-411. 
https://doi.org/10.1080/10494820903298662

Cho, M. H., \& Lim, S. (2017). Using regulation activities to improve undergraduate collaborative writing on wikis. Innovations in Education and Teaching International, 54(1), 53-61. https://doi.org/10.1080/14703297.2015.1117009

Chou, P., \& Chen, H. (2008). Engagement in online collaborative learning: A case study using a web 2.0 tool. Journal of Online Learning and Teaching, 4(4), 574-582.

Ciftci, H., \& Kocoglu, Z. (2012). Effects of peer e-feedback on Turkish EFL students' writing performance. Journal of Educational Computing Research, 46(1), 61-84. https://doi.org/10.2190/EC.46.1.c

Creswell, J. W. (2012). Educational research: Planning, conducting and evaluating quantitative and qualitative research (4th ed.). Boston, MA: Pearson.

Creswell, J. W., \& Clark, V. L. P. (2011). Designing and conducting mixed methods research (2nd ed.). Los Angeles: Sage Publications.

DiCamilla, F., \& Anton, M. (1997). The function of repetition in the collaborative discourse of L2 learners. The Canadian Modern Language Review, 53, 609-633.

Farrah, M. (2015). Online collaborative writing: Students' perception. Journal of Creative Practices in Language Learning and Teaching (CPLT), 3(2), 17-32.

Gokhale, A. A. (1995). Collaborative Learning Enhances Critical Thinking. Journal of Technology Education, 7(1), 22-30. https://doi.org/10.21061/jte.v7i1.a.2

Grami, G. M. A. (2012). Online collaborative writing for ESL learners using blogs and feedback checklists. English Language Teaching, 5(10), 43-48. https://doi.org/10.5539/elt.v5n10p43

Guasch, T., Espasa, A., Alvarez, I. M., \& Kirschner, P. A. (2013). Effects of feedback on collaborative writing in an online learning environment. Distance Education, 34(3), 324-338. https://doi.org/10.1080/01587919.2013.835772

Hirvela, A. (1999). Collaborative writing instruction and communities of readers and writers. TESOL Quarterly, 8(2), 7-12.

Katz, B. P., \& Thoren, E. (2014). WikiTextbooks: Designing Your Course Around a Collaborative Writing Project. Primus, 24(7), 574-593. https://doi.org/10.1080/10511970.2013.843625

Lowry, P. B., \& Nunamaker, J. F. (2003). Using internet-based, distributed collaborative writing tools to improve coordination and group awareness in writing teams. IEEE Transactions on Professional Communication, 46(4), 277-297. https://doi.org/10.1109/TPC.2003.819640

Nykopp, M., Marttunen, M., \& Erkens, G. (2019). Coordinating collaborative writing in an online environment. Journal of Computing in Higher Education, 31(3), 536-556. https://doi.org/10.1007/s12528-018-9203-3

Rahayu, E. S. (2016). Using Google Docs on collaborative writing technique for teaching English to non English department students. Proceedings of ISELT FBS Universitas Negeri Padang, 4(1), 226-236. http://ejournal.unp.ac.id/index.php/selt/article/view/6932/5466

Sajedi, S. P. (2014). Collaborative summary writing and EFL students' L2 development. Procedia Social and Behavioral Sciences, 98, 1650-1657. https://doi.org/10.1016/j.sbspro.2014.03.589

Shehadeh, A. (2011). Effects and student perceptions of collaborative writing in L2. Journal of Second Language Writing, 20(4), 286-305. https://doi.org/10.1016/j.jslw.2011.05.010 
Simonson, M., Smalldino, S., \& Zvacek, S. (2015). Teaching and learning at a distance: Foundations of distance education. In The Internet and Higher Education, 3(3), 219-222. https://doi.org/10.1016/S1096-7516(01)00034-3

Stoddart, A., Chan, J. Y. Y., \& Liu, G. Z. (2013). Enhancing successful outcomes of wiki-based collaborative writing: a state-of-the-art review of facilitation frameworks. Interactive Learning Environments, 24(1), 142-157. https://doi.org/10.1080/10494820.2013.825810

Storch, N. (2002). Patterns of interaction in ESL pair work. Language Learning, 52(1), 119-158. https://doi.org/10.1111/1467-9922.00179

Storch, N. (2005). Collaborative writing: Product, process, and students' reflections. Journal of Second Language Writing, 14(3), 153-173. https://doi.org/10.1016/j.jslw.2005.05.002

Storch, N. (2013). Collaborative writing in L2 classrooms. Multilingual Matters. doi:10.1111/j.modl.12255

Storch, N. (2019). Collaborative writing. Language Teaching, 52(1), 40-59. https://doi.org/10.1017/S0261444818000320

Such, B. (2019). Scaffolding English language learners for online collaborative writing activities. Interactive Learning Environments, 1-9. https://doi.org/10.1080/10494820.2019.1579233

Suwantarathip, O., \& Wichadee, S. (2014). The effects of collaborative writing activity using Google docs on students' writing abilities. Turkish Online Journal of Educational Technology, 13(2), $148-156$.

Swain, M. (1995). Three functions of output in second language learning. In G. Cook \& B. Seidlhofer (Eds.), Principle and practice in applied linguistics: Studies in honor of H.G. Widdowson (pp. 125-144). Oxford: Oxford University Press.

Swain, M., \& Lapkin, S. (1998). Interaction and second language learning: Two adolescent French immersion students working together. Modern Language Journal, 82, 320-337.

Wang, L. (2019). Effects of regulation on interaction pattern in web-based collaborative writing activity. Computer Assisted Language Learning, 0(0), 1-35. https://doi.org/10.1080/09588221.2019.1667831

Wang, Y. C. (2015). Promoting collaborative writing through wikis: a new approach for advancing innovative and active learning in an ESP context. Computer Assisted Language Learning, 28(6), 499-512. https://doi.org/10.1080/09588221.2014.881386

Wisdom, J., \& Creswell, J. W. (2013). Integrating quantitative and qualitative data collection and analysis while studying patient-centered medical home models. Agency for Healthcare Reseach and Quality, 13-0028-EF, 1-5. https://doi.org/No. 13-0028-EF.

Woodrich, M., \& Fan, Y. (2017). Google docs as a tool for collaborative writing in the middle school classroom. Journal of Information Technology Education: Research, 16(1), 391-410. https://doi.org/10.28945/3870

Zhou, W., Simpson, E., \& Domizi, D. P. (2012). Google Docs in an out-of-class collaborative writing activity. International Journal of Teaching and Learning in Higher Education, 24(3), 359-375. http://www.isetl.org/ijtlhe/ 


\section{$\underline{\text { AUTHOR'S BIO }}$}

Mohammed Alwaleedi, Ph.D., is currently employed by King Abdulaziz University in Saudi Arabia as an Assistant Professor in Applied Linguistics. He received a PhD in Applied Linguistics from the University of Queensland, and his doctoral project investigated the Collaborative Writing in Arabic as a Second language. Apart from Applied Linguistics, his ongoing research interests also include cultural studies. 